\title{
Statistical Measure of Validity of Financial Resources Allocation
}

\author{
Zhenghui Li ${ }^{1}$, Shuanglian Chen ${ }^{1 *}$, Silin Chen ${ }^{1}$ \\ ${ }^{1}$ Guangzhou Academy of International Finance and Guangzhou University, 510006, Guangzhou, P.R. CHINA
}

Received 6 June 2017 • Revised 19 September 2017 • Accepted 28 September 2017

\begin{abstract}
The validity of financial resources allocation is one of the elements assessing the ability of financial resources allocation. The validity of financial resources allocation is different from the efficiency of financial resources allocation. Therefore, in the current paper, we present precise definition for the validity of financial resources allocation and analyze its implication. Moreover, we discuss the relation between the validity of financial resources allocation and the economic development. We measure validity of financial resources allocation via appropriate models, since it could help assess the ability of financial resources allocation.
\end{abstract}

Keywords: statistical measure, validity of financial resources allocation, efficiency of financial resources allocation, DEA-Malmquist method

\section{THEORY OF VALIDITY OF FINANCIAL RESOURCES ALLOCATION}

\section{Definition of Validity of Financial Resources Allocation}

The definition of validity of financial resources allocation is ambiguous, most current research concentrates on the definition of efficiency of financial resources allocation. For example, Wang (1999), Tian (2013) and Song (2014) defined the efficiency of financial resources allocation as Pareto optimality of financial resources allocation, namely that any adjustment of financial resources cannot improve the efficiency of financial resources allocation. From the viewpoint of input-output, Yang (1998) compared the financial input factors (including the manpower resources, material resources and various kinds of financial assets) with economic outputs and then considered the efficiency of financial resources allocation as the efficiency of finance playing the role in the operation of national economy. From the same viewpoint, Chang (2010) considered the efficiency of financial resources allocation as the optimal economic benefit supported by different input factors such as manpower and material resources, and effective allocations from different industries or regions. The economic benefit is measured via the output and quality of finance and economics (Wang et al., 2016; Li et al., 2016). Turn to the research on validity of financial resources allocation. Cui (1999) claimed that validity of financial resources allocation is the valid allocation of financial resources formed by the intercoordination of social resources factor, economic resources factor and financial resources factor. On the other word, it is a financial behavior taking advantage reasonably of financial resources. Shen (2003) as well regarded the validity of financial resources allocation as a result of intercoordination among financial subsystems and intercoordination between financial system and economic system. Hu (2011) agreed with the viewpoint of Shen (2003) and emphasized that we should not only concentrate on the allocation of financial resources, but also care for the intercoordination between financial resources and economic resources.

No matter the validity of financial resources allocation or the efficiency of financial resources allocation, both of them should assess the ability of allocation of financial resources from the viewpoint of input-output of financial resources (Chang \& Wang, 2016). Although they have the coincident acknowledgement that allocation of financial resources devotes to obtaining the optimal economic benefit via various inputs of financial resources in different industries and regions. However, they are essentially discriminative. Efficiency of financial resources allocation includes efficiency of social resources allocation, efficiency of capital allocation in macroscopical level and production efficiency of individual unit, service and production efficiency of resources improved by technology, external financing in microscopical level (King et al., 1993; Demirguc-Kunt, 1998; Love, 2001; He, 2004; Liu, 2015). 


\section{Contribution of this paper to the literature}

- The scale efficiency is a stable factor affecting the validity of financial resources allocation. The economy affected the number of growth of generally technical efficiency strongly.

- The number of growth of validity of financial resources allocation was declining, which illustrated the weak result of financial resources supporting real economic development. Moreover, Finance developed rapidly. But real economy was recessionary. It was a problem that financial development could not promote economic development.

On the other hand, validity of financial resources allocation considers the outputs of financial resources as a production factor.

Following the arguments above, the current paper presents the definition of validity of financial resources allocation.

Definition. The validity of financial resources allocation is the degree of economic development realized by financial resources as a production factor realizing their functions. The validity of financial resources allocation can be regarded as Pareto optimality in theory. It also can be regarded as optimal proportion of input-output of financial resources in quantity.

The validity of financial resources allocation admits three implications:

Firstly, the proportion of input-output of financial resources is Pareto optimality periodically. We can see that as long as the proportion of input-output of financial resources stays in some range, any change of allocation of input factors cannot increase the outputs. This reasonable range cannot be decided by the financial resources itself, but decided by all the resources. The degree of such a range may be decided by the degree of alternative of resources as factors. Under the hypothesis that the economic development is promoted by capital and labor factors, if the capital marginal outputs are high, but the labor marginal outputs are low, the output proportion of financial resources factor may be relatively high; if the labor marginal outputs are high, but the capital marginal outputs are low, the output proportion of labor factor may be relatively high. In the analysis of really total factor production, we need to compare the marginal outputs of different factors and their degrees of alternative such that we can carry out the optimal allocation state. On the other hand, such an optimal state admits periodicity. Such a characteristic may change with the changings of objective of economic development, resources allocations and reconstruction of regimes.

Secondly, inputs of validity of financial resources allocation are the financial resources which are input into the real economy, including different kinds of financial resources. The recycle system of currency is classified into two levels. The first level is the cash flows between the central bank and other financial institutions. The second level is the cash flows between financial institutions and other institutions. The cash flows at different levels make different effects to the validity of financial resources allocation. The objective of cash flows between central bank and other financial institutions is implementing national financial policies. Since the national financial policies are implemented according to macro prudential regulation, such cash flows realize the functions that financial resources allocate other production factors. The cash flows between financial institutions and other institutions mean that financial resources are input into real economy directly. Such cash flows show the functions that financial resources are considered as production factors. Basing on the above argument, the validity of financial resources allocation means valid inputs. It can be considered as cash flows between financial institutions and other institutions in general sense. However, due to the core status of nonfinancial institutions in the national economy, the inputs of validity of financial resources allocation can be considered as the inputs from financial institutions to nonfinancial institutions. There are various kinds of input forms of financial resources, which depend on the relations to financial productions.

Thirdly, we not only need to consider the quantity of outputs of the validity of financial resources allocation, but also need to consider the quality. The essential functions of financial are serving the real economy. On the other hand, the economic development not only concerns about the quantity but also concerns about the quality. We concentrate on the scale and speed of economic development in quantity. On the other hand, we also concentrate on the adjustment of economic structure in quality. Meanwhile, economic structure can be represented by industrial structure.

\section{Validity of Financial Resources Allocation and Economic Development}

On the research of the relation between validity of financial resources allocation and economic development, many scholars have made contributions from various aspects, such as mechanism between financial resources allocation and economic development, relation between financial resources allocation and economic growth, adjustment of industrial structure, economic development promoted by finance. 
On the research about mechanism between financial resources allocation and economic development, some authors, for example, Gurley et al. (1960), Pagano (1993), Mu (1993), Han (2003), proposed that economic growth promoted by financial resources can be realized via savings ratio and savings-investment conversion ratio. Valid financial resources allocation can increase savings ratio and savings-investment conversion ratio, prompt economic investment, enlarge productions and outputs. Then the growth of industrial added value and economy can be realized. The economic growth prompts the income growth and then the saving growth. In a word, economic development and economic growth form a dynamical cocycle. The unimpeded mechanism between financial resources and real economy is necessary to realize capital accumulation and technological progress.

On the research about relation between financial resources allocation and economic growth, some results are about relation between financial intermediaries and economic growth, relation between stock market and economic growth, relation between industries and enterprises. Goldsmith (1969) early studied the relation between finance and economic growth. He measured the financial development by the ratio between asset value of financial intermediaries and GNP. He empirically analyzed such ratio for 35 countries from 1860-1963 and then found that financial development and economic growth were simultaneous. Tan (1999) empirically analyzed the relations among financial intermediaries, stock market and economic growth in China and then found the remarkably positive correlation between financial intermediaries and economic growth, as well as between financial intermediaries stock market. However, there existed remarkably negative correlation between stock market and economic growth. Zhao and Xue (2004) applied the model of output growth rate to studying relations among credit market, stock market and economic growth. He also found that credit market could prompt the economic growth. Nevertheless, stock market could not prompt the economic growth. Moreover, he also claimed that such a result may be due to the low use ratio of financing. Zou (2013) empirically studied the relation between financial resources allocation and economic growth. He found that financial deepening and development of financial market contribute to the economic growth more than the financial intermediaries and the level of financial opening up. Chen and Lin (2002) concluded that completed financial system could improve the financial resources allocation and then promote economic growth.

On research about relation between financial resources allocation and adjustment of industrial structure, Patrick illustrated the relation between financial development and industrial structure according to the theories of supplyleading and demand-following. He thought that financial development and adjustment of industrial structure were interactional. Wurgle (2000) measured industrial growth by total investment of manufacturing industry. He empirically tested relation between investments of manufacturing industry and industrial growths for 65 countries from 1963-1995. He found that financial development improved efficiency of capital allocation via financial market and then accelerated adjustment of industrial structure. Ma and Zhou (2007) quantified financial development and upgrade of industrial structure in China applying FIR, RFMR and FNAG. They empirically tested the relation between financial development and upgrade of industrial structure in China from 1978-2006. He found that there existed a long-term balance between financial development and upgrade of industrial structure and the financial development accelerated the upgrade of industrial structure. He also found that FIR played a more important role in upgrade of industrial structure than RFMR. However, there existed causality between RFMR and industrial structure. Kang (2013) studied the relation between financial development and adjustment of industrial structure in resource- based cities of China. He made a regression analysis with data of four resource-based cities (Laiwu, Dongying, Zaozuang, Zibo) in Shandong province from 1996-2008. He claimed that financial development could accelerate constitutionally the adjustment of industrial structure by optimizing financial resources allocation, improving validity of financial resources allocation and promoting innovation of financial development. Fan (2003) extended the research objects to regions and studied the relations between financial development and adjustment of industrial structure in east, middle and west of China. The results indicated that development of regional finance and the converting of structure could accelerate upgrade of regional industry structure and bridge the gap of regional economic development. $\mathrm{Li}$ (2015) pointed out that the increment of financial resources in east and middle may make positive influence for upgrade of industrial structure, nevertheless the case in west.

Finance comes from real economy. Promoting economic development should be the key object of financial development and financial resources allocation. On the research about relation between finance and real economy, Jian and Tan (2014) regarded real economy as the foundation of finance. On the other hand, finance may become an important tool promoting economic development by several ways such as promoting capital accumulation, optimizing resources allocation, dispersing operation risks, providing information platform and supervision platform. Wang (2014) pointed out that finance and real economy were mutually promoting. Financial innovation should also promote financial efficiency and then promote economic development. Valid financial resources allocation directly affected serviced efficiency of resources and benefit of real economy. Lu (2008), Liu et al. (2011), Jiang (2014), $\mathrm{Wu}$ (2014) found that financial distortions and uneven regional distribution of financial resources could lead to decline of validity of financial resources allocation, which would also lead to unbalance between economic structure and economic growth. Brandt (2013), Yang (2013) and Lu (2013) proposed several ways to guide financial resources inputting into real economy such as completing construction of financial market, specifying folk 
Table 1. Measure methods of financial resources allocation

\begin{tabular}{|c|c|c|}
\hline Methods & Objects & Reference \\
\hline \multirow{5}{*}{ DEA } & Measuring efficiency of financial resources allocation in China from 1995-2013 & Lei Liu (2015) \\
\hline & Measuring efficiency of financial resources allocation in some regions of China at 2008 & Hongmei Li (2012) \\
\hline & $\begin{array}{l}\text { Measuring efficiency of financial resources allocation for each provinces (cities) of } \\
\text { China from 2005-2007 }\end{array}$ & Shuai Chang (2010) \\
\hline & $\begin{array}{l}\text { Statically and dynamically empirical analysis of efficiency of financial resources } \\
\text { allocation for Hongkong, Shenzhen and Guangzhou }\end{array}$ & Ke Yuan (2008) \\
\hline & $\begin{array}{l}\text { Evaluation of efficiency of financial resources allocation for each province and east, } \\
\text { middle, west of China }\end{array}$ & Fei Liu (2007) \\
\hline PCA & $\begin{array}{l}\text { Comparing and measuring efficiency of financial resources allocation for villages of } \\
\text { each province (city) in west of China }\end{array}$ & $\begin{array}{l}\text { Qingsheng Tang \& Mingyi } \\
\text { Zhou (2009) }\end{array}$ \\
\hline $\begin{array}{l}\text { Factor } \\
\text { analysis }\end{array}$ & $\begin{array}{l}\text { Measuring efficiency of financial resources allocation for villages in Heilongjiang } \\
\text { Province }\end{array}$ & Bo Liu (2015) \\
\hline
\end{tabular}

financial development, promoting innovation of financial production, optimizing policies of financial credit, completing evaluation system, so that the validity of financial resources serving real economy could be promoted.

Financial system is the core of resources allocation in modern market economy. Other resources should be allocated by valid allocation of financial resources, namely that financial resources admit dual nature. Real economy is the foundation of finance. Finance is the product of real economy. Stressing the financial development without real economy would lead to inundation of financial capital and distortion of resources allocation. If finance separates from real economy, a mass of financial resources inputs into speculative market and then destroys the market order, even inducing crisis. Thus finance would lose its significance. Finance is an important tool promoting economic development. The positive influences of finance on real economic development could be summarized as two aspects. Firstly, finance provides a valid payment intermediation. Secondly, finance can help real economy realize capital accumulation, transform the accumulation into investment for enlarging production. Moreover, it undertakes the risk of the whole process and duty guaranteeing stable growth. Therefore, accumulation of financial resources not only provides fund demand for real economic development, but also undertakes and disperses risk, such that the real economy could developed stably and persistently.

\section{CONSTRUCTION OF MEASURE MODELS FOR VALIDITY OF FINANCIAL RESOURCES ALLOCATION}

\section{Comparing Measure Models for Efficiency of Financial Resources Allocation}

There are common and different features between validity and efficiency of financial resources allocation. As far as measure models, the validity of financial resources allocation should be investigated by factors. Therefore, there exists a strong relation between measure models for validity and efficiency of financial resources allocation. To select reasonable measure models for validity of financial resources allocation, the current paper will compare some measure models of efficiency, which are listed in Table 1.

The PCA (principal component analysis) and factor analysis are consistent in principle of calculation, namely that the core principle is the contribution of variance. PCA represents the linear combination of original variables by a new synthetic variable, and then measures the efficiency of financial resources allocation. The PCA and factor analysis need weighted average for each key factor. Hence, some units may obtain high scores due to the extremely high scores of one or several key factors, such that the objective evaluation is affected. DEA is a non-parametric method. It needs not to estimate the parameters in efficiency function such that it can deal with problems of large inputs and outputs. Moreover, the DEA needs not to translate scales and endow the weights. The popular method measuring efficiency of financial resources is DEA. Even so, the ability of DEA deeply analyzing information is a little weak.

The current paper applies DEA as the measure model for validity of financial resources allocation in basic level and then applies Malmquist exponent to obtaining deep information. The paper analyzes the validity of financial resources allocation via funding liquidity. The funding is regarded as input and the economic development is regarded as output. The funding liquidity between financial system and other institutions in real economy shows the characteristic of various inputs and outputs.

\section{Theory of Measure Model of Validity of Financial Resources Allocation}

DEA is an excellent model in analyzing efficiency. It uses a group of input-output sample values of multiple decision units (DMU) to evaluate the efficiency of the whole system. On the other hand, Malmquist exponent as 
developed several times and now it has been used widely in analyzing production efficiency. Hence, Malmquist exponent could also be used to analyze the validity of financial resources allocation.

The object of the application of Malmquist exponent in the current paper is calculating the valid exponent of financial resources allocation of China from 2002-2015. It is a problem on multiple inputs and outputs of a time series. The traditional DEA-Malmquist model needs DMU but cannot carry out efficient conclusions. Therefore, the current paper considers each month and each year as DMU. Then we calculate efficiency of financial resources allocation $T f p c h_{1}$ and $T f p c h_{2}$. Then we associate with these two quantities to obtain the valid exponent of financial resources allocation $E$.

For each DMU, the vector $x_{i}$ represents the input financial resources in $i^{\text {th }}$ DMU. Vector $y_{i}$ represents the output of real economy in $i^{\text {th }}$ DMU. The Malmquist exponent in $t^{\text {th }}$ period can be expressed as

$$
M_{0}^{t}\left(x_{t+1}, y_{t+1}, x_{t}, y_{t}\right)=\frac{D_{0}^{t}\left(x_{t+1}, y_{t+1}\right)}{D_{0}^{t}\left(x_{t}, y_{t}\right)} \text {. }
$$

The Malmquist exponent (denoted by Tfpch in the following argument) from $t^{\text {th }}$ to $t+1^{\text {st }}$ period can be expressed as

$$
M_{0}^{t}\left(x_{t+1}, y_{t+1}, x_{t}, y_{t}\right)=\left[\frac{D_{0}^{t}\left(x_{t+1}, y_{t+1}\right)}{D_{0}^{t}\left(x_{t}, y_{t}\right)} \times \frac{D_{0}^{t+1}\left(x_{t+1}, y_{t+1}\right)}{D_{0}^{t+1}\left(x_{t}, y_{t}\right)}\right]^{\frac{1}{2}} .
$$

$D_{0}^{t}$ and $D_{0}^{t+1}$ are distance functions in $t^{\text {th }}$ and $t+1^{\text {st }}$ period. The reference substance is the Tfpch in $t^{\text {th }}$ period.

Fare (1994) decomposed Tfpch exponent into efficiency variation (Effch) and technical progress (Techch). Furthermore, he analyzed the construction of production efficiency. $T f p c h$ can be expressed as

where

$$
M_{0}^{t}\left(x_{t+1}, y_{t+1}, x_{t}, y_{t}\right)=\frac{D_{0}^{t+1}\left(x_{t+1}, y_{t+1}\right)}{D_{0}^{t}\left(x_{t}, y_{t}\right)} \times\left[\frac{D_{0}^{t}\left(x_{t+1}, y_{t+1}\right)}{D_{0}^{t+1}\left(x_{t+1}, y_{t+1}\right)} \times \frac{D_{0}^{t}\left(x_{t}, y_{t}\right)}{D_{0}^{t+1}\left(x_{t}, y_{t}\right)}\right]^{\frac{1}{2}},
$$

$$
\begin{gathered}
\text { Techch }=\frac{D_{0}^{t+1}\left(x_{t+1}, y_{t+1}\right)}{D_{0}^{t}\left(x_{t}, y_{t}\right)}, \\
\text { Effch }=\left[\frac{D_{0}^{t}\left(x_{t+1}, y_{t+1}\right)}{D_{0}^{t+1}\left(x_{t+1}, y_{t+1}\right)} \times \frac{D_{0}^{t}\left(x_{t}, y_{t}\right)}{D_{0}^{t+1}\left(x_{t}, y_{t}\right)}\right]^{\frac{1}{2}} .
\end{gathered}
$$

The Effch in (3.5) then can be decomposed into pure technical efficiency Pech and scale efficiency Sech, where Sech represents the growth of DMU efficiency led by the growth of financial resources scale. The Teffch, constituted by Pech multiplying by Techch, represents the total of all factors affecting the efficiency of financial resources allocation, namely that the generally technical efficiency,

$$
\text { Teffch }=\text { Pech } \times \text { Techch. }
$$

Finally, $T f p c h$ can be decomposed by Teffch and Sech, such that we can analyze the essential reason causing the variation of $T f p c h$. It can be expressed as

$$
\text { Tfpch }=\text { Teff } \times \text { Sech. }
$$

Since we consider each month and each year as DMU, we would obtain two results of financial resources allocation. The current paper obtains valid exponent of financial resources allocation by calculating the geometric mean of these two results, namely that

$$
\begin{aligned}
& E=\sqrt{T f p c h_{1} \times T f p c h}{ }_{2}=\sqrt{\text { Teffch } h_{1} \times \text { Sech }_{1}} \times \sqrt{\text { Teffch } h_{2} \times \text { Sech }_{2}}
\end{aligned}
$$

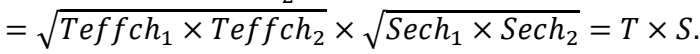

If $E>1$ for some DMU in some period, then the validity of financial resources allocation in the current period is higher than the last period, but not vice versa. If $S>1$, then the quantity of financial resources allocation in the current year is higher than the last year, but not vice versa. If $T>1$, then the generally technical efficiency in the current year is higher than the last year, but not vice versa.

\section{Selection of Model Variables and Data Sources}

Before applying DEA-Malmquist model to measuring efficiency of financial resources allocation, we need to specify the indexes of inputs and outputs. DEA-Malmquist model firstly selects the indexes of inputs and outputs. The selection of indexes of inputs and outputs would affect directly the calculation of DMU. Hence, we need to select these indexes prudently.

Yuan (2008) selected factor of financial human resources, factor of financial credit resources, factor of insurance resources, factor of government resources as the input factors when studying the efficiency of financial resources 
Table 2. Indexes of input-output of validity of financial resources allocation

\begin{tabular}{|c|c|c|c|}
\hline $\begin{array}{l}\text { Index } \\
\text { category }\end{array}$ & Index name & Index implication & Data sources \\
\hline \multirow{3}{*}{ Input } & $\begin{array}{l}\text { Credit rights for } \\
\text { nonfinancial } \\
\text { institutions }\end{array}$ & $\begin{array}{l}\text { This index is the net worth of credit rights form deposit } \\
\text { companies to enterprises. It reflects the degree of inputs of } \\
\text { financial resources of nonfinancial institutions. }\end{array}$ & $\begin{array}{l}\text { Overview of deposit companies in } \\
\text { the website of People's Bank of } \\
\text { China }\end{array}$ \\
\hline & $\begin{array}{l}\text { Various kinds of } \\
\text { loans }\end{array}$ & $\begin{array}{l}\text { This index indicates the total loans provided by financial } \\
\text { institutions. It reflects the degree of input of financial } \\
\text { resources of financial institutions. }\end{array}$ & $\begin{array}{l}\text { RMB credit balance sheet of } \\
\text { financial institutions in the website } \\
\text { of People's Bank of China }\end{array}$ \\
\hline & $\begin{array}{l}\text { Circulation of } \\
\text { government bond }\end{array}$ & $\begin{array}{l}\text { This index is the bond issued by government for collecting } \\
\text { money. It reflects the degree of input of financial resources } \\
\text { of government. }\end{array}$ & Wind data \\
\hline \multirow{3}{*}{ Output } & $\begin{array}{l}\text { Industrial added } \\
\text { value }\end{array}$ & $\begin{array}{l}\text { This index indicates the final results of industrial production } \\
\text { expressed as currency. It reflects the degree of production in } \\
\text { real economy. }\end{array}$ & $\begin{array}{l}\text { Economic data from the website of } \\
\text { national research }\end{array}$ \\
\hline & $\begin{array}{l}\text { Total retail sales of } \\
\text { consumer goods }\end{array}$ & $\begin{array}{l}\text { This index is the CONSU of urban and rural residents and } \\
\text { social groups bought from wholescale business, retail } \\
\text { business, hotel business, catering business and other } \\
\text { business. }\end{array}$ & Website of State Statistics Bureau \\
\hline & $\begin{array}{l}\text { Coefficient of } \\
\text { industrial structure }\end{array}$ & $\begin{array}{l}\text { This index is according to theory of evolution of industrial } \\
\text { structure and considers added value of primary industry as } \\
\text { fiducial value. Then it evaluates secondary industryand } \\
\text { tertiary industry and associates with these two results to } \\
\text { obtain the coefficient of industrial structure. }\end{array}$ & Website of State Statistics Bureau \\
\hline
\end{tabular}

allocation of Hong Kong, Shenzhen and Guangzhou. The output factor is the added value of financial industry. Li and Xiang (2010) selected the number of staff in financial institutions, gross of agricultural loans of financial institutions, financial expenditure and capital investment of financial industry as input indexes. Per capita income of peasants and per capita GDP of primary industry are selected as output indexes. Then they evaluated and compared the efficiency of financial resources allocation of villages in China. Wang (2008) selected loan-to-deposit ratio of all financial institutions as the input indexes when applying DEA to evaluate the distribution of financial resources in China. GDP, outstanding of deposits of all financial institutions, outstanding loan of all financial institutions are selected as output indexes.

The existing research enlightens the selection of indexes in the current paper. For the calculation of efficiency of financial resources allocation, most scholars selected suitable indexes according to macroeconomic data and then applied DEA to calculating the efficiency of financial resources allocation. Such selection of indexes can reflect the level of financial resources allocation, which guarantees the completeness of indexes system. These researches regarded the society as entirety and studied the efficiency of financial resources allocation from a macro viewpoint.

However, there exists distinction between validity and efficiency of financial resources allocation. The validity of financial resources allocation is merely a dimension of ability of financial resources allocation. In reality, it is strongly related to degree of the institutions taking part into financial resources allocation. Each institution affects differently the ability of financial resources allocation. Financial and nonfinancial institutions are directly related to the ability of financial resources allocation. Therefore, there exists distinction between validity and efficiency of financial resources allocation in the selection of indexes for validity as an important dimension of ability of financial resources allocation.

The current paper measures the validity of financial resources allocation from the viewpoint of fund flow, according to the object of the paper. It reflects the ability of finance serving real economy. The output indexes not only include quantity, but also include qualitative indexes of economic structure. According to such principle and the representativeness of financial resources in qualitative aspect, the input and output indexes of validity of financial resources allocation include credit rights for nonfinancial institutions, various kinds of loans, Circulation of government debt. Since the validity of financial resources allocation is according to the object that finance serves real economy, therefore, the selection of output indexes should reflect the gross and structure of economic development. At the same time, to keep the consistency of data frequency of inputs and outputs, since we cannot obtain month indexes of GDP, the current paper selects the industrial added value to representing the GDP for the strong correlation between them. Hence, the output indexes include industrial added value, total retail scale of consumer goods, coefficient of industrial structure. The input indexes are presented in Table 2. 
EURASIA J Math Sci and Tech Ed

Table 3. Scale efficiency of financial resources allocation from 2002 to 2015

\begin{tabular}{|c|c|c|c|c|c|c|c|c|c|c|c|c|c|}
\hline Year & Jan & Feb & Mar & Apr & May & Jun & Jul & Aug & Sep & Oct & Nov & Dec & Mean \\
\hline 2002 & 1.000 & 1.000 & 1.000 & 1.000 & 1.000 & 1.000 & 1.000 & 1.000 & 1.000 & 1.000 & 1.000 & 1.000 & 1.000 \\
\hline 2003 & 1.000 & 1.010 & 1.000 & 1.011 & 0.938 & 1.036 & 0.986 & 0.978 & 0.984 & 0.990 & 0.974 & 1.000 & 0.992 \\
\hline 2004 & 1.000 & 0.990 & 0.995 & 1.011 & 0.974 & 1.048 & 1.018 & 1.020 & 1.002 & 1.016 & 1.030 & 0.993 & 1.008 \\
\hline 2005 & 1.000 & 1.014 & 1.002 & 0.990 & 1.007 & 1.013 & 0.992 & 1.006 & 1.004 & 1.002 & 1.000 & 1.000 & 1.003 \\
\hline 2006 & 1.000 & 1.003 & 1.000 & 1.006 & 0.986 & 0.997 & 1.002 & 0.996 & 1.004 & 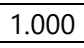 & 0.995 & 38 & 0.998 \\
\hline 2007 & 1.000 & 0.993 & 1.000 & 0.987 & 1.014 & 1.002 & 1.001 & 0.997 & 0.998 & 1.000 & 0.999 & 0.993 & 0.999 \\
\hline 2008 & 1.000 & 0.999 & 1.000 & 1.019 & 0.985 & 0.987 & 0.991 & 0.991 & 1.001 & 1.000 & 1.001 & 1.000 & 0.998 \\
\hline 2009 & 1.000 & 0.976 & 1.018 & 0.985 & 1.018 & 1.004 & 1.018 & 0.975 & 0.985 & 1.0 & 0.999 & 0.993 & 0.998 \\
\hline 2010 & 1.000 & 1.029 & 0.980 & 1.005 & 0.995 & 1.013 & 0.999 & 0.983 & 1.011 & 0.992 & 0.991 & 0.983 & 0.999 \\
\hline 2011 & 1.000 & 0.995 & 1.017 & 1.002 & 1.005 & 1.005 & 0.975 & 0.997 & 0.980 & 0.979 & 1.000 & 0.984 & 0.995 \\
\hline 2012 & 1.000 & 1.026 & 1.005 & 0.993 & 0.993 & 1.015 & 0.990 & 1.039 & 1.027 & 0.993 & 1.011 & 0.986 & 1.007 \\
\hline 2013 & 1.000 & 0.994 & 1.033 & 1.011 & 1.010 & 1.008 & 0.999 & 1.015 & 0.996 & 0.994 & 0.998 & 0.983 & 1.004 \\
\hline 2014 & 1.000 & 1.021 & 1.004 & 0.998 & 1.002 & 0.995 & 0.963 & 1.014 & 1.003 & 0.993 & 1.008 & 0.980 & 0.999 \\
\hline 2015 & 1.000 & 1.022 & 1.012 & 0.995 & 0.999 & 0.997 & 1.011 & 1.003 & 0.965 & 1.023 & 0.995 & 0.968 & 0.999 \\
\hline
\end{tabular}

Table 4. General technical efficiency of financial resources allocation from 2002 to 2015

\begin{tabular}{|c|c|c|c|c|c|c|c|c|c|c|c|c|c|}
\hline Year & Jan & Feb & Mar & Apr & May & Jun & Jul & Aug & Sep & Oct & Nov & Dec & Mean \\
\hline 2002 & 1.000 & 0.997 & 1.019 & 0.850 & 1.035 & 1.004 & 0.897 & 1.024 & 1.037 & 0.919 & 1.036 & 1.035 & 0.988 \\
\hline 2003 & 0.994 & 1.066 & 0.999 & 0.805 & 0.971 & 1.022 & 0.930 & 1.051 & 0.992 & 0.938 & 1.028 & 0.968 & 0.980 \\
\hline 2004 & 0.959 & 0.977 & 0.872 & 0.881 & 0.987 & 0.937 & 0.902 & 0.964 & 1.018 & 0.950 & 0.952 & 1.066 & 0.955 \\
\hline 2005 & 0.928 & 0.853 & 0.906 & 0.851 & 0.985 & 0.993 & 0.959 & 0.995 & 1.033 & .987 & .037 & 16 & 0.970 \\
\hline 2006 & 1.018 & 0.998 & 0.982 & 0.882 & 1.034 & 1.021 & 0.948 & 0.971 & 1.019 & 0.992 & 0.958 & 1.026 & 0.988 \\
\hline 2007 & 0.969 & 0.907 & 0.942 & 0.948 & 1.006 & 0.933 & 0.992 & 0.947 & 1.014 & 1.009 & 0.986 & 1.057 & 0.976 \\
\hline 2008 & 0.919 & 0.863 & 0.863 & 0.812 & 0.891 & 0.850 & 0.854 & 0.924 & 0.937 & 0.958 & 0.938 & 1.032 & 0.903 \\
\hline 2009 & 0.935 & 0.868 & 0.850 & 0.900 & 0.913 & 0.867 & 0.894 & 0.974 & 1.011 & 1.018 & 1.001 & 1.065 & 0.941 \\
\hline 2010 & 0.977 & 0.941 & 0.999 & 1.063 & 1.087 & 0.996 & 1.031 & 1.050 & 1.043 & 1.028 & 0.931 & 1.038 & 1.015 \\
\hline 2011 & 0.949 & 0.926 & 0.885 & 0.870 & 0.944 & 0.981 & 0.998 & 0.978 & 1.053 & 1.040 & 0.984 & 1.067 & 0.973 \\
\hline 2012 & 0.994 & 0.990 & 0.917 & 0.989 & 1.044 & 0.963 & 0.975 & 0.951 & 1.007 & 1.015 & 0.973 & 1.063 & 0.990 \\
\hline 2013 & 0.840 & 0.763 & 0.891 & 0.952 & 0.976 & 0.948 & 0.965 & 0.988 & 1.037 & 1.008 & 0.959 & 1.037 & 0.947 \\
\hline 2014 & 0.954 & 0.917 & 0.932 & 0.931 & 0.999 & 0.974 & 0.951 & 0.880 & 0.970 & 0.961 & 0.920 & 1.042 & 0.953 \\
\hline 2015 & 0.894 & 0.862 & 0.874 & 0.876 & 0.934 & 0.873 & 0.864 & 0.965 & 0.942 & 0.985 & 0.968 & 0.986 & 0.919 \\
\hline
\end{tabular}

\section{CALCULATION OF VALIDITY OF FINANCIAL RESOURCES ALLOCATION}

\section{Analysis of Validity of Financial Resources Allocation}

According to the theory of validity of financial resources allocation, the current paper applies DEA-Malmquist model to measuring the efficiency. More precisely, we calculate the scale efficiency, generally technical efficiency and exponent of validity of financial resources allocation from 2002-2015 by software DEAP 2.1. The results of scale efficiency of financial resources allocation are shown in Table 3.

$\mathrm{S}$ (scale efficiency of financial resources allocation) reflects the degree of validity of financial resources allocation enhanced by enlarging the quantity of financial resources. It represents the monthly variety ratio of scale efficiency. The basic period is January 2002 and $S=1 . S>1$ means growth of the scale efficiency in the current month, but not vice versa.

We can see that from Table 3, the scale efficiency of financial resources allocation is stationary from 2002-2015. Only the means of scale efficiency in 2004, 2005, 2012 and 2014 are larger than one, where the maximum is 1.008 in 2004. Others are less than one, which illustrates that the growth of validity of financial resources allocation is not realized by enlarging the quantity of financial resources.

We can see that from 2002-2015, the month maximums of scale efficiency are 1.000, 1.036, 1.048, 1.014, 1.006, $1.014,1.019,1.018,1.029,1.017,1.039,1.033,1.021,1.023$ in order. The month minimums of scale efficiency are 1.000, $0.938,0.974,0.990,0.986,0.987,0.985,0.975,0.980,0.975,0.986,0.983,0.963,0.965$ in order. The maximum is 1.048 in Jun, 2004 and the minimum is 0.938 in May, 2003. There are some values of scale efficiency larger than one or smaller than one, which implies that the scale efficiency of financial resources allocation in China is stationary.

The results of generally technical efficiency of financial resources allocation are shown in the Table 4 . 
Table 5. Exponents of validity of financial resources allocation from 2002 to 2015

\begin{tabular}{|c|c|c|c|c|c|c|c|c|c|c|c|c|c|}
\hline Year & Jan & Feb & Mar & Apr & May & Jun & Jul & Aug & Sep & Oct & Nov & Dec & Mean \\
\hline 2002 & 1.000 & 0.997 & 1.019 & 0.850 & 1.035 & 1.004 & 0.897 & 1.024 & 1.037 & 0.919 & 1.036 & 1.035 & 0.988 \\
\hline 2003 & 0.994 & 1.077 & 0.999 & 0.815 & 0.910 & 1.059 & 0.916 & 1.027 & 0.976 & 0.928 & 1.001 & 0.968 & 0.973 \\
\hline 2004 & 0.959 & 0.967 & 0.868 & 0.890 & 0.961 & 0.981 & 0.919 & 0.983 & & .965 & 80 & & .963 \\
\hline 2005 & 0.928 & 0.865 & 908 & 0.843 & 0.993 & 1.006 & 0.951 & 001 & .037 & 990 & 037 & 116 & 973 \\
\hline 2006 & 1.018 & 1.002 & 0.982 & 0.888 & 1.020 & 1.018 & 0.951 & 0.968 & 1.024 & 0.992 & & 1.014 & 0.986 \\
\hline 2007 & 0.969 & 0.901 & 0.942 & 0.935 & 1.020 & 0.935 & 0.993 & 0.945 & 1.0 & 1.009 & & 1.050 & 0.975 \\
\hline 2008 & 0.919 & 0.8 & 0.863 & 0.8 & & 0.8 & 0.847 & 0.9 & & 00 & & & 2 \\
\hline 2009 & 0.935 & 0.847 & 0.866 & 0.886 & 0.930 & 0.870 & 0.910 & 0.950 & 0.996 & 1.025 & 1.000 & 1.058 & 0.939 \\
\hline 2010 & 0.977 & 0.968 & 0.979 & 1.069 & 1.082 & 1.009 & 1.031 & 1.033 & 1.054 & 1.020 & 0.922 & & 1.014 \\
\hline 2011 & 0.949 & 0.922 & 0.900 & 0.873 & & & & & & & & & 0.968 \\
\hline 2012 & 0.994 & & 0.922 & & & & & & & & & & .996 \\
\hline 2013 & 0.840 & 0.758 & 0.920 & 0.963 & 0.987 & 0.956 & 0.963 & 1.003 & 1.033 & 1.002 & 0.957 & 1.020 & 0.950 \\
\hline 2014 & 0.954 & 0.936 & 0.936 & 0.929 & 1.000 & 0.969 & 0.916 & 0.893 & 0.972 & 0.955 & 0.928 & 1.021 & 0.951 \\
\hline 2015 & 0.894 & 0.880 & 0.885 & 0.871 & 0.934 & 0.871 & 0.873 & 0.968 & 0.909 & 1.008 & 0.963 & 0.954 & 0.917 \\
\hline
\end{tabular}

Table 6. Statistic of DEA-Malmquist model

\begin{tabular}{ccccccccc}
\hline & Mean & Median & Standard deviation & Variance & Kurtosis & Skewness & Minimum & Maximum \\
\hline $\mathrm{S}$ & 0.99987 & 1.00000 & 0.01420 & 0.00020 & 2.77596 & -0.17656 & 0.93754 & 1.04800 \\
\hline $\mathrm{T}$ & 0.96416 & 0.97085 & 0.06349 & 0.00403 & -0.13196 & -0.42390 & 0.76283 & 1.11629 \\
\hline $\mathrm{E}$ & 0.96386 & 0.96896 & 0.06212 & 0.00386 & -0.05292 & -0.46001 & 0.75795 & 1.11629 \\
\hline
\end{tabular}

T reflects generally technical efficiency. Table 4 is similar to Table 3. From Table 4 we can see that from 20022015 , the generally technical efficiency of financial resources allocation is fluctuating. We can see that only the generally technical efficiency of financial resources allocation in mean in 2010 is larger than one. Others are smaller than one. The minimum is 0.903 in 2008 , which implies that the generally technical efficiency restricts the validity of financial resources allocation.

We can see from 2002-2015 that, the month maximums of generally technical efficiency are 1.037, 1.066, 1.066, $1.116,1.034,1.057,1.032,1.065,1.087,1.067,1.063,1.037,1.042,0.986$ in order. The month minimums of generally technical efficiency are $0.85,0.805,0.872,0.851,0.882,0.907,0.812,0.85,0.931,0.87,0.917,0.763,0.88,0.862$. The maximum is 1.116 in December 2005. The minimum is 0.763 in February 2013. All the values of generally technical efficiency in 2015 are smaller than one, which implies that the generally technical efficiency was falling in 2015.

The results of exponents of validity of financial resources allocation are shown in Table 5.

$\mathrm{E}$ (exponents of validity of financial resources allocation) reflects the validity of financial resources allocation. Table 5 is similar to Table 3. From Table 5 we can see that from 2002 to 2015, the exponents of validity of financial resources allocation are fluctuating strongly. Only the exponent of validity in mean in 2010 is larger than one. The others are less than one. The minimum is 0.902 in 2008, which implies that the validity of financial resources allocation was falling. The financial development was separating from economic development.

We can see that from 2002 to 2015, the month maximums of validity of financial resources allocation are 1.037, $1.077,1.059,1.116,1.024,1.05,1.032,1.058,1.082,1.05,1.048,1.033,1.021,1.008$ in order. The month minimums of validity of financial resources allocation are $0.85,0.815,0.868,0.843,0.888,0.901,0.827,0.847,0.922,0.873,0.922$, $0.758,0.893,0.871$ in order. The maximum is 1.116 in December 2005. The minimum is 0.758 in February 2013. We can see that the deviation between the minimum and one is larger than the deviation between the maximum and one, which illustrates that the validity of financial resources allocation in China was falling.

Table 6 shows the fluctuation of validity of financial resources allocation.

The means of S, T and E are $0.99987,0.96416$ and 0.96386 respectively. The results imply that $\mathrm{E}$ admits the trend of falling, which caused by the falling of $S$ and T. The standard deviations of S, T and E are 0.01420, 0.06349 and 0.06212 . These results imply that the fluctuations of $\mathrm{T}$ and $\mathrm{E}$ are stronger than $\mathrm{S}$. The kurtosis and skewness of $\mathrm{S}$ are 2.77596 and -0.17656 , which illustrates that the distribution of $S$ admits left-of-center peak. The kurtosis and skewness of $\mathrm{T}$ are -0.13196 and -0.42390 , which illustrates that the distribution of $\mathrm{T}$ is approximately normal with left-of-center flat hump. The kurtosis and skewness of E are -0.05292 and -0.46001 , which illustrates that the distribution of $\mathrm{E}$ more approximates to normal distribution than $\mathrm{S}$ and $\mathrm{T}$, although it also admits left-of-center flat hump. From maximums and minimums, we also can see that the ranges of $\mathrm{T}$ and $\mathrm{E}$ are larger than $\mathrm{S}$, which illustrates they are fluctuating more strongly than S. 


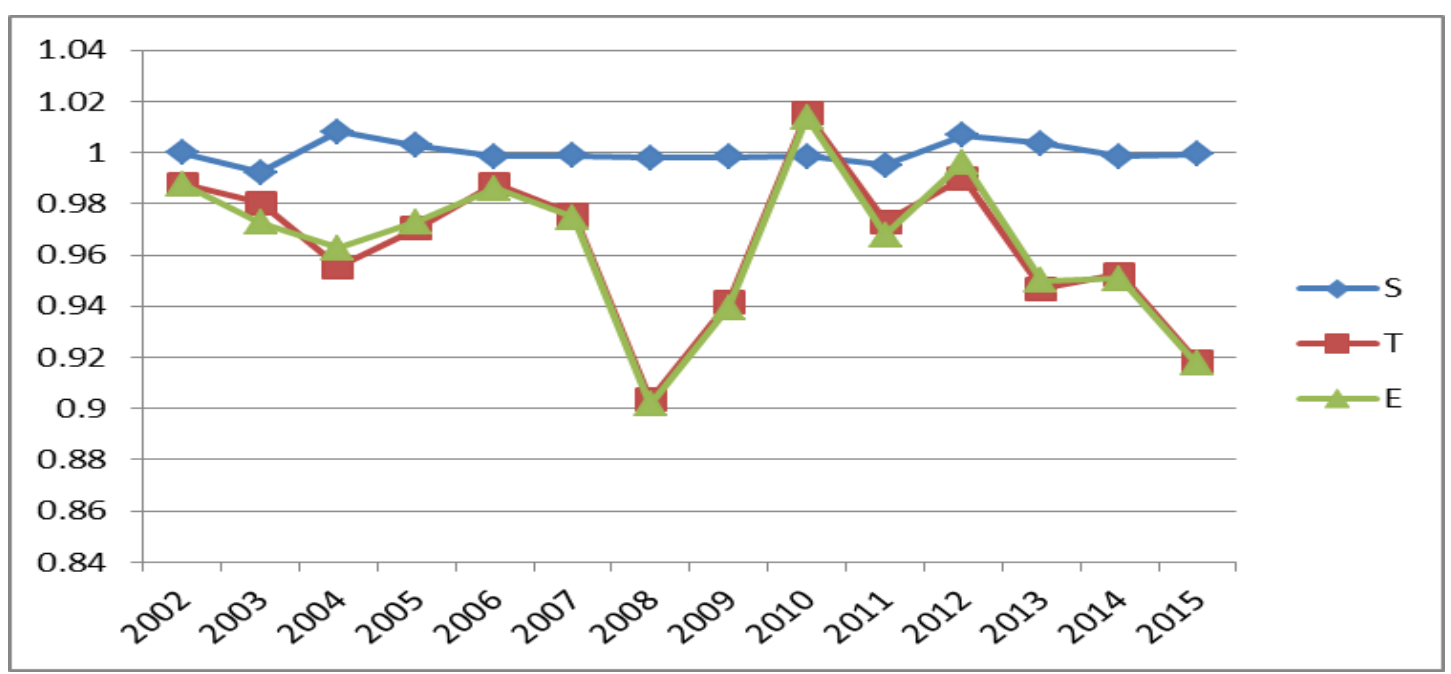

Figure 1. Time series of validity of financial resources allocation

\section{Analysis for Characteristics of Validity of Financial Resources Allocation}

According to Tables 3, 4 and 5, we present the time series plot of validity of financial resources allocation (see Figure 1).

From Figure 1, we can see that $S$ is stationary, which illustrates that scale efficiency makes no remarkable difference to the validity of financial resources allocation. On the other hand, generally technical efficiency $\mathrm{T}$ and exponent of validity of financial resources allocation $\mathrm{E}$ are fluctuating. Moreover, the fluctuation tendencies of $\mathrm{T}$ and $\mathrm{E}$ are similar, which implies that generally technical efficiency of financial resources allocation $\mathrm{T}$ makes remarkable difference to the validity of financial resources allocation E.

We can see from Figure 1 that the range of validity of financial resources allocation is 0.90-1.02 from 2002-2015. The validity of financial resources allocation from 2002 to 2006 is relatively stationary. However, it is fluctuating obviously from 2007 to 2015. Relating to the development of Chinese technology, the Chinese technology at the beginning of the $21^{\text {st }}$ century was stationary as well as the efficiency of financial resources allocation. Subsequently, American subprime mortgage crisis in 2007 and financial tsunami in 2008 made a mass of difference to the validity of financial resources allocation of China such that the validity of financial resources allocation fell sharply. Subsequently, getting rid of the influence of American subprime mortgage crisis and financial tsunami, the economy operated placidly. The validity of financial resources allocation grew in 2009 and 2010. From 2011 to 2015, the validity of financial resources allocation fell mildly. The technical efficiency was the key factor. The technical development suffered choke out and the technical efficiency fell stably.

For understanding deeply, the annual cases of scale efficiency, generally technical efficiency and validity of financial resources allocation, we calculate the number of months whose values are larger than one and plot the distribution of efficiency growth (see Figure 2).

From Figure 2, we can see that number of growth of scale efficiency is reposeful from 2003-2015. The number of growth of scale efficiency is between three and seven. The biggest number of growth is located between 2003 and 2004. The smallest number of growth is located between 2007 and 2008. This illustrates that scale efficiency is a stable factor affecting the validity of financial resources allocation.

From 2002 to 2015, the variation of the number of growth of generally technical efficiency is a little strong. The biggest number of growth is seven in 2002 and 2010. The smallest number of growth is zero in 2015. The economy affected the number of growth of generally technical efficiency strongly. The number of growth of the generally technical efficiency fell rapidly due to financial tsunami in 2008. The number of growth of generally technical efficiency grew rapidly in 2009 and 2010, since it was benefited from the investment of four trillion. Subsequently, the disadvantage of massive investment was appearing, the economic development of China was falling with a new normalcy. The number of growth of generally technical efficiency in 2015 stood in a declining state.

From 2002 to 2015, the variations of number of growth of validity of financial resources allocation and generally technical efficiency are similar. The maximum number of growth is eight in 2002 and 2010 . The minimum number of growth is one in 2008, 2014 and 2015. The number of growth of validity of financial resources allocation was declining, which illustrated the weak result of financial resources supporting real economic development. 


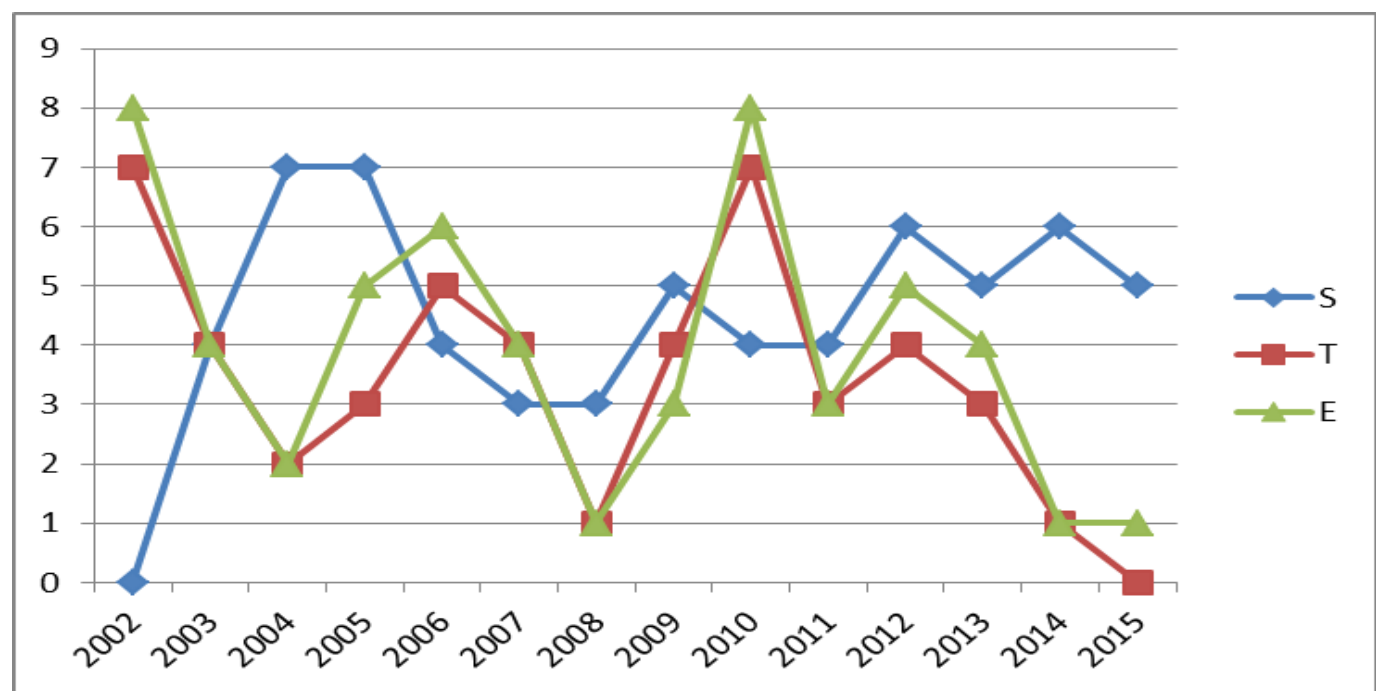

Figure 2. Distribution of efficiency growth of financial resources allocation

Moreover, such phenomenon persisted. Finance developed rapidly. But real economy was recessionary. It was a problem that financial development could not promote economic development.

\section{CONCLUSION}

The current paper presents a definition for validity of financial resources allocation. Then we empirically analyze the validity of financial resources allocation by reasonable models. The paper can be summarized as the following three aspects:

Firstly, we present a precise definition for validity of financial resources allocation and point out that the validity of financial resources allocation measures the degree of economic development promoted by financial resources as production factors. The validity is Pareto optimality in theory. It is the optimal proportion between inputs and outputs of financial resources in quantity.

Secondly, we apply DEA-Malmquist model to calculating the validity of financial resources allocation. Then we give interpretations for the model variables in DEA-Malmquist model. We select credit rights of nonfinancial institutions, total of different kinds of loan and circulation of government bonds as the indexes of input according to fund flow. Then we select industrial added value, total retail sales of consumer goods and coefficient of industrial structure as the indexes of output according production, circulation and economic structure of real economy.

Thirdly, we empirically analyze the validity of financial resources allocation. From the empirical results, the validity of financial resources allocation is mainly affected by generally technical efficiency. The validity of financial resources allocation was falling from 2002 to 2015. The financial development and economic development were separating from each other.

\section{REFERENCES}

Chang, S. (2010). Empirical Analysis of Evaluation of Efficiency of Financial Resources Allocation and Influence Factors, Press of Jinan University.

Chang, T. C., \& Wang, H. (2016). A Multi Criteria Group Decision-making Model for Teacher Evaluation in Higher Education Based on Cloud Model and Decision Tree. Eurasia Journal of Mathematics, Science E Technology Education, 12(5).

Cui, M. (1999). Theory research of financial resources (II): financial resources, Financial Forum, (5), 10-15.

$\mathrm{Hu}$, B. (2011). Research on Financial Resources Allocation of Henan Province, Press of Ningbo University.

King, R., \& Levine, R. (1993). Finance and growth: Schumpeter might be right, Quarterly Journal of Economics, 108(3), 713-717.

Li, J., \& Xiang, L. (2010). Analysis of efficiency of financial resources allocation for villages via DEA, Finance and Accounting Monthly, (7), 40-43.

Li, Z., Wang, Z. \& Huang, Z. (2016). Modeling Business Cycle with Financial Shocks Basing on Kaldor-Kalecki Model. Quantitative Finance and Economics, 1(1), 44-66. 
Liu, B. (2015). Research on Evaluation of Financial Resources Allocation for Villages in Heilongiang Province, Press of HIT. Liu, X., \& Zhou, Y. (2011). Test of relation between financial resources and real economy, Financial Research, (2), 5770.

Lu, X. (2008). Does misallocation of financial resources hinder the economic growth of China, Financial Research, (4), 55-68.

Wang, C. Y., Lv, X. H., \& Zhao, S. K. (2016). The Relative Efficiencies of Research Universities of Science and Technology in China: Based on the Data Envelopment Analysis and Stochastic Frontier Analysis. Eurasia Journal of Mathematics, Science E Technology Education, 12(10).

Wang, X., \& Han, L. (2008). Evaluation of validity for distribution of financial resources in China via DEA, Journal of Beijing University of Aeronautics and Astronautics, 21(4), 4-7.

Wang, Z (1999). Financial Efficiency - Theory and Practice of Optimal Configuration of Financial Resources, Press of Northeast university of finance and economics.

Wurgler, J. (2000). Financial markets and the allocation of capital, Journal of Financial Economics, 58(1-2), 187-214.

Yuan, K. (2008). Empirical Research on financial resources allocation in HongKong, ShenZhen and Guangzhou, Press of Jinan University.

Zou, J. (2013). Research on Relation between Financial Resources Allocation and Economic Growth, Press of Hainan University.

\section{http://www.ejmste.com}

